\title{
Sexualidade feminina em revista(s)
}

Luciana Patrícia Zucco

Maria Cecília de Souza Minayo²

ZUCCO, L.P.; MINAYO, M.C.S. Female sexuality in magazines. Interface - Comunic., Saúde, Educ., v.13, n.28, p.43-54, jan./mar. 2009.

This paper results from an investigation on the discourse of female sexuality carried by women's magazines in the years 2005 and 2006. 'Claudia' and 'Mulher dia-a-dia' were the documents analyzed through a qualitative investigative approach. The data construction was undertaken through critical discourse analysis, and female sexuality was approached from a constructivist perspective. The main results showed that the discursive conventions present in the reports gave shape to dual positions on contemporary Western sexual dynamics, such as: adoption of symmetrical sexual practices versus continuation of asymmetrical sexual practices; female sexual autonomy versus female sexual dependency; activeness versus passiveness; female pleasure versus male pleasure. Thus, we argue that sexuality remains doubly informed by hegemonic standards in force within society.

Key words: Female sexuality. Media. Discourse. Periodicals.
Este artigo é resultado da investigação dos discursos da sexualidade feminina veiculados por revistas para mulheres no período de 2005 e 2006. 'Claudia' e 'Mulher dia-a-dia', foram os documentos analisados em uma abordagem qualitativa de pesquisa. A construção dos dados ocorreu por meio da análise crítica de discurso, sendo a sexualidade feminina abordada com base em uma leitura construtivista. Os principais resultados evidenciaram que as convenções discursivas presentes nas reportagens materializaram posições duais sobre a dinâmica sexual contemporânea e ocidental, como: adoção de práticas sexuais simétricas versus vigência de práticas sexuais assimétricas; autonomia sexual feminina versus dependência sexual feminina; atividade versus passividade; prazer feminino versus prazer masculino. Afirmamos, com isso, que a sexualidade permanece duplamente informada por padrões hegemônicos vigentes na sociedade.

Palavras-chave: Sexualidade feminina. Mídia. Discursos. Publicações periódicas.
${ }^{1}$ Assistente social. Departamento de Política Social e Serviço Social Aplicado, Escola de Serviço Social, Universidade Federal do Rio de Janeiro. Rua Bartolomeu Portela, 36/202 - Botafogo. Rio de Janeiro, RJ, Brasil. 22.290-190 Ipzucco@uol.com.br ${ }^{2}$ Socióloga. Fundação Oswaldo Cruz. 


\section{Introdução e contextualização}

O objetivo deste artigo é evidenciar como as revistas destinadas a mulheres veiculam a sexualidade feminina. Nele apresentamos dados de uma pesquisa finalizada em 2007, em que os documentos analisados foram retirados das revistas 'Claudia' e 'Mulher dia-a-dia', dos anos de 2005 e 2006, ambas de ampla circulação no momento da investigação, e que veiculam conteúdos de interesse da mulher. O relatório da Empresa Unilever (Etcoff et al., 2004) considera, num entendimento global, como "interesse da mulher", matérias sobre beleza, bem-estar e relação entre esses elementos, reforçando o discurso dos que creditam aos meios de comunicação o poder de atingir a individualidade das pessoas. Ao abordar as perspectivas femininas ressaltadas pela mídia, a pesquisa que deu origem a este artigo revelou serem beleza e aparência física os mais relevantes aspectos considerados como imperativos pelas mulheres $\mathrm{e}$ recompensados pela sanção da sociedade.

Neste artigo, fazemos um exercício de análise de discurso com as duas citadas revistas, evidenciando que a comunicação atua de forma preponderante na sociedade contemporânea, com repercussões na vida social e, sobretudo, na subjetividade (Thompson, 1998). Esse poder indiscutível tem a ver, entre outros fatores, com os meios técnicos de comunicação, responsáveis pela configuração de valores e símbolos para o público usuário de seus serviços. Eles alimentam o mercado publicitário, definem imagens, ditam padrões e vendem produtos, compondo um mosaico que acaba por integrar a maneira de nos percebermos e de estarmos no mundo.

Estudos (Fujisawa, 2006; Caldas Coulthard, 2005; Mira, 2003; Monteiro, 2000; Medrado, 1997) sobre meios técnicos de comunicação específicos, como televisão e revistas, demonstram, ainda, quanto são paradoxais as mensagens divulgadas à sociedade por esses veículos. Simultaneamente, difundem discursos emblemáticos de novos tempos e outros reificadores de concepções e crenças estabelecidas, assim como discursos educativos e erotizados, atendendo tanto às transformações socioculturais da sociedade como aprofundando estereótipos que garantem o conservadorismo.

Se, por um lado, sua importância na vida cotidiana das pessoas é um fato, por outro, os meios de comunicação se valem desse cotidiano e retiram dele a matéria necessária para criar identificação com o público leitor - geram demanda e se mantêm num universo de concorrência. Logo, eles reconstroem a dinâmica cotidiana a seu modo, fazendo dela, quase sempre, um grande espetáculo.

Segundo Melo (2000), nos anos 90, houve no Brasil uma mudança editorial promovida pela grande imprensa. Jornais e revistas de circulação nacional ampliaram os espaços destinados a temas como comportamento, sexualidade, saúde e saúde reprodutiva, bem como deram vez à participação de leitores e leitoras. Atualmente, estes são chamados a se posicionar sobre políticas públicas e serviços, até mesmo sobre a criação de seções voltadas para os direitos do consumidor. Tais mudanças decorrem de uma conjunção de fatores, apontadas pela autora, como: interesses do mercado, evolução editorial, comportamento mais crítico da sociedade, e abertura de temas da agenda social e política a segmentos organizados da sociedade.

No caso das revistas femininas, o influxo da Conferência Mundial sobre a Mulher (CMM), realizada em Pequim, em 1995, manifestou-se como um acontecimento histórico que se soma às mudanças mencionadas e as corrobora. A Plataforma de Ação da $\mathrm{CMM}^{3}$, da qual o Brasil é signatário, traz, no capítulo J, elementos para o debate sobre a relação entre a mulher e os meios de

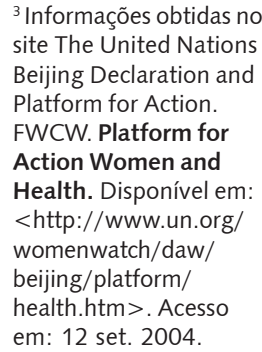


${ }^{4} \mathrm{O}$ Código Brasileiro de Autorregulamentação Publicitária (22/5/1980), instrumento de autodisciplina para a atividade de propaganda comercial, na Seção 1 Preâmbulo, artigo $7^{\circ}$, reconhece que a publicidade exerce forte influência de ordem cultural sobre grandes massas da população, e prevê, com isso, o acompanhamento e a fiscalização da atividade publicitária. Informações obtidas no site do Conselho Nacional de Autorregulamentação Publicitária (CONAR), disponível em: <http:// www.conar.org.br $>$. comunicação. Esse capítulo apresenta alguns objetivos: (a) ampliação do acesso da mulher a esses meios e sua participação na expressão de idéias e na tomada de decisões das mídias; (b) acesso às novas tecnologias de comunicação; (c) promoção de uma imagem feminina equilibrada e não estereotipada nesses meios.

No âmbito da Plataforma de Ação da CMM, a área "mulher e meios de comunicação" é considerada estratégica para o fortalecimento das mulheres, embora tenha registrado o menor número de iniciativas e avanços políticos (Melo, 2000). O capítulo J reafirma a necessidade de se realizarem estudos a respeito da temática, e de que esta seja acompanhada de pesquisas e fiscalização ${ }^{4}$, para que, com um conjunto de informações e novos conhecimentos, órgãos públicos, privados e organizações não governamentais (ONG) possam ser subsidiados em suas intervenções relacionadas ao desenvolvimento da mulher.

Este artigo apresenta a seguinte sequência de temas: aspectos conceituais sobre gênero e sexualidade feminina; questões metodológicas, que esclarecem o caminho percorrido; discussão dos resultados e conclusões.

\section{Aspectos conceituais sobre gênero e sexualidade}

A sexualidade é aqui discutida a partir de seu processo de desnaturalização e de reconstrução, tal como é tratada por alguns autores, como Bozon (2004), Foucault (1999) e Giddens (1993), que não a limitam a comportamentos ou práticas sexuais. Esses estudiosos ampliam a análise dos aspectos culturais, das dimensões políticas e sociais que envolvem a sexualidade, desvinculando a da reprodução biológica da espécie. Por isso, se distanciam do paradigma das ciências biomédicas. Para Bozon (2004, p.15), a visão não naturalista "sublinha ao mesmo tempo a flexibilidade, a expressividade e a mobilidade da esfera sexual na época contemporânea e sua inevitável dependência dos processos sociais que a constroem".

Duas posições demarcam o debate sobre sexualidade: o essencialismo e o construtivismo social. A teoria essencialista credita à sexualidade aspectos inatos ou naturais e a considera imutável, engessando-a na ordem biológica. Persiste nessa leitura o primado de condutas, atos e relacionamentos sociais determinados pelo sexual, o que significa assinalar que homens e mulheres são providos de atributos diferentes em virtude de suas características anatomofisiológicas. Essa lógica vincula a sexualidade ao corpo e a reduz às funções biológicas, naturalizando-a e sugerindo que todos os sujeitos a compartilham como condição universal.

Diferentemente do essencialismo, no qual predomina a racionalidade médico-científica e psicanalítica, o construtivismo social congrega abordagens que problematizam a universalidade dos instintos sexuais. Nesse caso, a orientação, os sentidos e a noção de experiência ou de comportamento sexuais não são passíveis de generalizações. Tais aspectos estariam sustentados por um conjunto de significados articulados a outras referências, como: o sistema de parentesco e de gênero, as classificações etárias, a origem social, as crenças religiosas, entre outras.

A abordagem construtivista remete o entendimento da sexualidade à ordem da cultura. Isso sugere a produção de explicações específicas sobre o tema, associadas ou não à reprodução. Tal leitura possibilita, igualmente, tratar a sexualidade como uma construção subjetiva e coletiva, que acontece de acordo com as especificidades de um período histórico e de um ambiente determinado (Heilborn, 1996).

Além das duas perspectivas identificadas acima, o debate atual sobre a sexualidade nas Ciências Humanas e Sociais permite quatro afirmações. Primeiro, a 
sexualidade é pesquisada e analisada como um sistema articulado a outros subsistemas, constituindo-se num campo de conhecimento em construção e de investigação em si, dotado de certa legitimidade. Segundo, existe uma espécie de concorrência na definição do que seja sexualidade. Terceiro, posições teóricas relativas à temática possibilitam identificar que o vínculo entre sexualidade e reprodução é tão construído socialmente quanto a leitura na qual a sexualidade é totalmente distanciada do processo reprodutivo. E, quarto, a sexualidade feminina figura como desdobramento das diferentes abordagens, não se constituindo numa discussão solta e desvinculada.

Neste artigo definimos sexualidade feminina considerando a relação entre subsistemas de gênero e identidade social, segundo uma leitura construtivista. A adoção desses parâmetros deve-se ao fato de remeterem à construção do sujeito, ordenando uma determinada maneira de olhar como as mulheres vivem e demonstram sua sexualidade.

Segundo Butler (2003), a categoria gênero não é fixa e imutável, mas sim temporária e performativa, permitindo, com isso, a desnaturalização das práticas de significação envolvidas na apreensão do que é feminino e masculino. Isso situa a heterossexualidade e o falocentrismo no âmbito de regimes de poder e de campos discursivos. Dessa forma, gênero é demarcado como categoria de organização das relações sociais, que tem como elemento central a idéia da hierarquia. Paradoxalmente, a categoria gênero consagra a discussão crítica da idéia naturalizada das concepções de homem e de mulher. Estas não são fixas ou atreladas à noção de sexo. Em outras palavras, a categoria gênero aponta para a nãocontinuidade entre sexo físico e sexo social, e que tem sido utilizada por diversos campos do conhecimento (Heilborn, 1996).

Ao diferenciar a dimensão biológica da social, a categoria de gênero explicita que os atributos constitutivos da sexualidade feminina foram historicamente construídos de forma assimétrica e em oposição aos masculinos. Contudo, as discussões de gênero permitem afirmar que não é a diferença sexual que institui relações hierárquicas de modo assimétrico entre homens e mulheres, mas a maneira como cada sociedade valoriza e significa tais diferenças biológicas. Disso decorrem representações sobre o que se espera do feminino e do masculino, de seus comportamentos e de suas atitudes, até mesmo sexuais.

\section{Materiais e métodos: conhecendo o caminho}

Utilizamos a abordagem qualitativa na pesquisa que deu origem a este texto (Minayo, 2007). Construímos os dados por meio da análise crítica de discurso (ACD). Essa modalidade metodológica se volta para a apreensão da percepção sutil, da valorização do dito e do não-dito, da entrelinha e do detalhe presentes na prática discursiva. Sua atenção não se centra na comprovação de questões falsas ou verdadeiras, pois a análise não busca a explicação dos fatos. Sua lógica é expor as perspectivas e os processos pelos quais os fatos podem ser vistos, uma vez que os discursos desenham um campo de efeitos de sentidos, e não apenas um efeito específico.

O conjunto do material de pesquisa envolve 12 exemplares da revista 'Claudia' (Editora Abril, R\$ 8,60) e 12 exemplares da revista 'Mulher dia-a-dia' (Editora Alto Astral, $R \$ 4,90$ ), ambas publicadas mensalmente e relativas aos anos de 2005 e 2006. A análise inclui chamadas das capas das revistas e matérias de 'Claudia' e 'Mulher dia-a-dia'. Consideramos as capas indicadores para a seleção das matérias, porque elas atuam como grandes letreiros de divulgação do conteúdo e da forma que a leitora encontrará no corpo do texto. De acordo com Caldas Coulthard (2005), as manchetes são verdadeiras sínteses dos assuntos abordados, além de se caracterizarem como persuasivas e autopromocionais. $O$ material selecionado é justificado pela argumentação de Orlandi $(2001,1999)$, que assegura não ser intenção da análise de discurso a exaustividade, ou seja, a análise horizontal, tampouco a completude ou exaustividade em relação ao objeto empírico, pois ele é inesgotável. A exaustividade esperada é a vertical, por possibilitar a análise em profundidade e por trazer consequências teóricas relevantes, uma vez que não trata os dados como meras ilustrações.

A escolha de 'Claudia' ocorreu por sua longa permanência no mercado e por ter sido pioneira no âmbito da imprensa feminina, ao inaugurar, em 1961, data de sua criação, um novo estilo de editar 
${ }^{5}$ Informações obtidas no site da Editora Abril: <http:// publicidade.abril.com.br/ homes.php?MARCA=

13>. Acesso em: 2 abr. 2003.

${ }^{6}$ Informações obtidas no site da Editora Alto Astral: <http:// www.editoraaltoastral. com.br $>$. Acesso em: 3 jun. 2006. moda, beleza, culinária e decoração (Buitoni, 1986). 'Claudia' trouxe um editorial especializado e propôs assuntos práticos e da vida cotidiana, carregados de representação sobre o feminino. Sua tiragem é de 471.700 exemplares e sua circulação líquida é de 374.210 exemplares. Seu público compreende mulheres (86\%) de classe social B (44\%), na faixa etária de 18 a 39 anos $(52 \%)^{5}$. Ela tem, como foco, a mulher adulta, contemporânea, que gosta de se cuidar e de se sentir bonita e amada.

Diferentemente de 'Claudia', a revista 'Mulher dia-a-dia', por ocasião da pesquisa, estava no seu primeiro ano de circulação, tendo sido lançada em março de 2005. Dela falaremos no tempo verbal pretérito, pois ao final de 2006 já havia sido retirada do mercado. A tiragem era de 44.340 exemplares e a circulação líquida de 13.326 exemplares. Seu público compreendia mulheres (79\%) de classe social C (42\%), na faixa etária de vinte a 29 anos (22\%), e na de cinquenta anos em diante $(19 \%)^{6}$. Sua atenção voltava-se para diversos temas de interesse da mulher, como moda, beleza, saúde, comportamento, família, bem-estar, profissão, entre outros, atuando como um guia para o universo feminino. Por ser uma publicação nova no mercado, 'Mulher dia-a-dia' fazia um contraponto com 'Claudia' em vários aspectos, como, por exemplo, não possuir assinaturas e ser encontrada, à época, apenas em bancas de jornal. Esses atributos valorizavam ainda mais a importância de sua capa. 'Mulher dia-a-dia' também tinha um preço inferior e mais accessível que 'Claudia'.

Em um primeiro momento, recorremos à análise textual das chamadas e matérias, descrevendo-as (microanálise). Para tanto, ativemo-nos ao vocabulário, pronomes, verbos e adjetivos empregados. Com base na análise desses elementos linguísticos, observados em seu conjunto, nos textos selecionados de cada exemplar, e em sua interação com os demais, podemos identificar a relação estabelecida entre magazine e leitora, bem como os lugares e assuntos destinados ao feminino e à sexualidade feminina. Para, então, apreendermos os sentidos da prática discursiva à luz da prática social (macroanálise).

\section{Resultados}

Considerando o nível de detalhamento da análise textual, optamos por apresentar a análise de alguns textos e a formação discursiva dos magazines, sem, contudo, esgotar o processo de construção dos dados. 'Claudia' e 'Mulher dia-a-dia' instituem um padrão de discursividade que marca a forma como a sexualidade feminina é difundida, sendo pela sua identificação que iniciamos a discussão dos resultados.

\section{Em cena: 'Claudia' e 'Mulher dia-a-dia'}

'Claudia' e 'Mulher dia-a-dia' não possuem uma homogeneidade em suas práticas discursivas, na medida em que apresentam tendências diferentes. $\mathrm{O}$ tipo de discurso que mais se destaca em ambos os magazines indica o espaço social designado às revistas e às leitoras, bem como os valores sociais pertinentes, ou seja, o lugar social da produção do texto. Portanto, os magazines constroem relações diferenciadas com as leitoras, sendo por meio destas que os temas são veiculados.

'Claudia' estabelece modos horizontais de interagir com suas leitoras e utiliza um conjunto de recursos linguísticos. Um deles é a interlocução direta, implicando as leitoras nos textos que disponibiliza e as convidando a se inteirarem das informações. A presença do pronome de tratamento "você", do pronome pessoal "nós" e dos pronomes possessivos (seu, sua, nossa, nosso), tanto nas chamadas como nas matérias, são um dado recorrente e prevalente: - "Que tal [você] começar uma coisa 
nova? Oportunidades se abrem quando [nós] conquistamos um território desconhecido" (maio, 2005); "Nossos filhos globalizados. As perspectivas que surgem aqui e lá fora. Os seus estão bem preparados?" (agosto, 2005).

Cabe destacar que elementos de igualdade e de democracia são transmitidos pelo pronome inclusivo "nós", que também simboliza uma fala destinada a pessoas comuns, como argumenta Fairclough (2001). O pronome "nós" sugere, assim, que a revista assume uma posição social similar à da leitora, partilhando situações e constituindo relações de identificação.

Outra expressão desse vínculo de relações correspondentes são as frases estruturadas em forma de pergunta: "A aventura espiritual do sexo tântrico. Será que vai ser bom para vocês?" (maio de 2005). "Por que o cabelo mexe tanto com as nossas emoções" (setembro 2005). O uso dessa construção indica o fato de que 'Claudia' considera terem suas leitoras alguma informação e as reconhece em condições de comentar seus questionamentos. É importante sinalizar que a relação de proximidade instituída pelo magazine com a leitora é reafirmada pela associação dos diferentes recursos - questões e pronomes - nos enunciados, uma vez que demarca a tendência de cumplicidade presente em seus discursos.

A revista utiliza, ainda, o interdiscurso para impregnar a comunicação de um sentido de troca e estabelecer uma relação de simetria - "Entrevista Eve Ensler, Dos monólogos da vagina ao desespero com a barriga, uma viagem pelo corpo da mulher (maio 2005)". Para tratar de assuntos como corpo e estética femininos, 'Claudia' recorre à autora da peça de teatro "Monólogos da Vagina", Eve Ensler. O magazine se utiliza desse conjunto de formulações, que requer conhecimento prévio da leitora de um evento teatral, para que ela compreenda a mensagem que está subliminarmente colocada.

Da mesma forma, a edição de novembro de 2005 traz: "A mulher de 30 e o amor. O que está acontecendo com nossas Bridget Jones". Nesse enunciado, o interdiscurso recupera um filme britânico, do gênero comédia romântica (2001), para questionar e sugerir que as mulheres brasileiras e leitoras de 'Claudia' - daí o pronome inclusivo "nossas" - permanecem sem relacionamento afetivo,

diferentemente do que aconteceu com a protagonista do filme. Outrossim, o interdiscurso aponta que o público de 'Claudia' tem acesso a diferentes meios de comunicação e é inteirado dos acontecimentos sociais de sua realidade. Revela, igualmente, um vínculo de cumplicidade entre os sujeitos da comunicação e demonstra a distribuição social de poder pela linguagem, uma vez que informações e culturas podem ser reconhecidas e compartilhadas.

Distintamente de 'Claudia', a prática discursiva identificada em 'Mulher dia a dia' indicava um traço hierárquico entre revista e leitora. Este era instituído, entre outros recursos, pelo modo verbal imperativo. Verbos que denotam ordens - 'acabe', 'perca', 'conheça', 'entre', 'descubra', 'saiba', 'seduza', 'faça', 'fique' - fizeram parte dos textos do magazine. A revista assumia a posição de protagonista, que preordenava o universo de discurso do seu público e o colocava como conduzido. Sua imagem era de porta-voz das informações não disponíveis às leitoras e que eram objetivamente imperiosas para elas.

Nessa perspectiva, o verbo imperativo era associado ora a conselhos - "Lição de conquista! Aprenda com as estrelas da novela América" (setembro, 2005), ora a números - "9 hidratantes tudo de bom. Escolha o seu e faça um carinho em seu corpo" (junho, 2005). É importante destacar que aconselhamento e quantidade eram recorrentes nos enunciados de 'Mulher dia a dia': " 12 dicas para dar um show de sedução!" (setembro, 2005); "10 lições para criar filhos felizes" (dezembro, 2005).

Se "dicas", "lições" ou "guias" garantiram ao magazine a imagem de conhecedor das demandas femininas, os números conferiram exatidão e confiabilidade. Ademais, essas expressões recuperaram, simbolicamente, a idéia de funcionalidade, ações autoaplicadas e caminho infalível, desde que as leitoras seguissem os passos apresentados pela revista. Nesse sentido, o enunciado "Pense como campeã e VENÇA na vida" prescrevia atitudes indefectíveis e fáceis; além disso, ordenava à leitora que assumisse uma postura mental propositiva para que pudesse conquistar sucesso, sugerindo que ela ainda não o detinha.

Na mesma edição de julho (2005), o discurso direto da atriz Eliane Giardini - "Eu não sou uma pessoa de ficar de braços cruzados, esperando as coisas acontecerem" - trazia a metáfora de "braços cruzados". Esta fazia referência à sua personalidade determinada e ativa. Somado a isso, sua imagem estampava a capa da revista e remetia à personagem Neuta, da novela 'América', de grande projeção à época, 
símbolo de força, coragem e empreendedorismo. Esses elementos em uma mesma superfície textual reforçaram o sentido de que cabia ao público de 'Mulher dia-a-dia 'desenvolver seu protagonismo.

Tais características estiveram presentes tanto no magazine como em suas modelos, e estimularam identificação com a leitora, pois o discurso direto reproduzia, na sua originalidade, as palavras das celebridades e demarcava vozes diferenciadas - as delas e a voz da revista. Em última instância, eram as próprias celebridades comentando aspectos de sua cotidianidade para a leitora. O discurso da figura pública trazia uma fala privada, o que favorecia a criação de vínculos de proximidade e destoava da tendência discursiva do magazine.

Na sequência, "Novidade! Histórias de mulheres que alcançaram o sucesso!". O substantivo "novidade" demonstrava, igualmente, que competência e sucesso eram predicados recentes do 'universo feminino', desse modo, motivo de desejo e de aprendizado, inclusive para a leitora. Simbolicamente, ela era associada à imagem das 'mulheres' de 'Mulher dia-a-dia', para ser estimulada e ensinada a ser capaz. A despeito dos dois últimos enunciados versarem sobre o mesmo campo semântico, havia neles um contraponto explícito: as 'mulheres do magazine' já ocupavam o lugar de vencedora, enquanto a leitora ainda não.

Embora as práticas discursivas em 'Claudia' e em 'Mulher dia a dia' apresentem tendências específicas, as semelhanças residem nos assuntos veiculados. Isso implica observarmos que um mesmo domínio temático pode ser apresentado distintamente, dependendo da forma como é enquadrado no texto, da relação estabelecida com a leitora e da classe social a que se destina.

\section{Sexualidade feminina em 'Claudia' e em 'Mulher dia-a-dia'}

As revistas delineiam um "universo" considerado por elas como feminino, já extensamente problematizado por várias estudiosas em diferentes décadas (Caldas-Coulthard, 2005; Widholzer, 2005; Swain, 2001; Bassanezi, 1996; Sarti, Moraes, 1980; Friedan, 1971). O questionamento diz respeito à leitura essencialista presente na noção de "universo feminino", que naturaliza, reproduz e mantém a hierarquia social entre homens e mulheres. Em vários momentos na análise, explícita ou implicitamente, a construção do "mundo feminino" é realizada em oposição ao "mundo masculino", e vice-versa. Essa oposição demarca signos distintos entre homens e mulheres e, até mesmo, antagônicos a ambos, reportando à construção binária de gênero (Heilborn, 1999). É segundo esse conjunto de elementos que demarcam o 'universo feminino' nas duas revistas que situamos os discursos sobre a sexualidade feminina.

'Claudia' apresenta uma estrutura de disposição dos assuntos que se repete nas edições, com pouca variação. Estes são divididos em grandes blocos, compreendendo cinco temas: sexualidade, subjetividade (realização pessoal e autoestima), âmbito privado (filhos e finanças), moda e beleza (autocuidado). $O$ magazine enfatiza: beleza, imagem feminina, corpo, relacionamento amoroso entre homem e mulher, realização pessoal, condição feminina, filhos e, com mais ênfase, tabus sexuais e sexo.

Na chamada "Mais amor. Histórias improváveis com final feliz mostram a força da paixão" ('Claudia', junho 2005), o advérbio de intensidade "mais" sinaliza tanto a constância do assunto na revista quanto o interesse da leitora pelo tema. Tal sentido é, transversalmente, reafirmado pelo enunciado da edição de dezembro de 2005: "Sim, existe amor após a separação. Nossa repórter pesquisa e comprova". Por meio deste, a revista responde afirmativamente à indagação de seu público, sugerindo que relacionamento amoroso mobiliza a produção do magazine e demanda, igualmente, ações investigativas sobre o tema por parte da equipe.

Outrossim, 'Claudia' utiliza-se da prática discursiva simétrica para colocar em pauta esse tema, que é um dos valores femininos tidos como o núcleo mais ativo da cultura de massa. Amor é destaque em todas as edições do magazine e está associado aos valores práticos fundamentais àquela cultura (Morin, 1997). Precisamente por isso, e porque recuperam dimensões do cotidiano, os valores femininos (afirmação da individualidade privada, bem-estar, amor e felicidade) geram identificações e instigam a imitação, o consumo e a conduta promovida pelo veículo de comunicação.

A chamada "Operação resgate para recolocar VOCÊ em primeiro lugar". "Não, não é egoísmo. É essencial!" volta-se diretamente para a leitora, por meio do pronome de tratamento "você", e alude ao 
fato de ela ter uma série de atribuições. A metáfora "operação resgate" sinaliza a importância de a leitora de 'Claudia' ser recuperada e libertada da situação em que se encontra. Este sentido é acentuado pela seta vermelha que precede "Você" e que indica, figurativamente, para onde a atenção deve ser direcionada. Logo, reproduz uma interlocução ao responder que "não é egoísmo" a mulher restituir o cuidado para consigo, pois este está voltado para o outro, seja este família, filhos, casa ou trabalho, como sugere o adjetivo "primeiro".

Contraditoriamente, o discurso "O lanche saudável para a escola". "Nesse menu visual, seus filhos escolhem o jeito mais saboroso de escapar da onda de obesidade que assola o Brasil" recoloca a atenção da mulher voltada para este outro, que, no caso, é motivo de preocupação e de seu trabalho. A revista a designa como mãe, por meio do pronome possessivo "seus", e menciona como uma de suas atribuições: o cuidado com a alimentação dos filhos, a promoção de hábitos alimentares, e as suas escolhas alimentares. De forma simplista, reproduz o senso comum de que cabe à mulher o cuidado com a alimentação, seja da família ou dos filhos. Novamente, a mulher ocupa, no discurso da revista, a posição de sujeito, chegando a ser responsabilizada pela ausência de ações voltadas para consigo ou para com o outro.

"+ bonita!" precede os enunciados listados e organizados por marcadores: [1] "Os segredos das experts: dermatologistas, professoras de ginástica e nutricionistas revelam como cuidam da pele, quais seus exercícios preferidos e o cardápio ideal"; [2] "Massagens que modelam o corpo, diminuem a barriga, afinam a cintura, reduzem os pneus". O sinal gráfico "+" sugere que as matérias intensificarão a beleza de que as leitoras de 'Claudia' são possuidoras.

No primeiro enunciado, o adjetivo "experts" atua como um selo de garantia às informações, pois são especialistas discorrendo sobre o assunto, consequentemente, profissionais apresentando a forma mais adequada de cuidado com a estética e a alimentação, o que atribui um status de veracidade à matéria. Corroborando tal afirmação, a preposição "das" remete aos depoimentos pessoais. Isso revela aspectos particulares e não divulgados da vida das "experts", bem como traz o depoimento de mulheres destinado às leitoras, ou seja, são mulheres 'falando' para mulheres. Destacamos, igualmente, que, nesse enunciado, o cotidiano ganha relevância e o que, antes, era circunscrito ao domínio do privado se torna público, cabendo à revista essa exposição.

No segundo, são oferecidos recursos para que a leitora possa desencadear uma ação, que, neste caso, consiste em esculpir o corpo, mediante um padrão subentendido, para torná-lo mais bonito. Todos os verbos - modelar, diminuir, afinar, reduzir - se referem ao ato de ajustar, e dão à leitora a noção de redução de medidas como uma possibilidade da massagem. Esses verbos, polissemicamente, associam resultados de massagem ao de intervenções cirúrgicas. De qualquer forma, ambas as técnicas tratam de um investimento realizado pela mulher para obter o corpo desejado. A metáfora "pneus", pejorativamente, faz alusão à gordura e remete ao conjunto de cuidado com a estética necessário para tornar a mulher ainda mais bonita.

Na edição de março de 2005, a revista indaga: "Ainda existem tabus sexuais em pleno século 21? 12 ótimas respostas". Porém, o enunciado deixa pistas sobre a posição do magazine, ao utilizar o advérbio "ainda" na construção do texto. Ou seja, revela surpresa diante da existência de tabus sexuais na atualidade e oferece à leitora um conjunto de respostas que considera qualificado. Na sequência, o advérbio "MAIS:" liga o primeiro enunciado ao segundo: "Por que não podemos ver a sexualidade de ALEXANDRE, O GRANDE, com os olhos de hoje". Reafirmando tal estruturação, o sinal gráfico - dois pontos - permite que este último desenvolva o que foi colocado anteriormente, dando continuidade ao assunto, como sendo um único texto.

A intertextualidade - "Alexandre, o Grande" - faz referência ao título do filme em cartaz naquele momento e à história do rei da Macedônia, bem como explicita um dos tabus sexuais da contemporaneidade, o da homossexualidade masculina. Nesse sentido, a revista explicita que, ao abordar sexo ou relacionamento sexual nas demais edições, o faz segundo a orientação heterossexual. 'Claudia', de forma sutil, dá visibilidade em seu discurso ao tema da homossexualidade, o que geralmente fica oculto nas revistas para mulheres, ou seja, leva-o para o público feminino. Especificamente em relação ao sexo, este magazine difere de 'Mulher dia-a-dia', que o privilegiava e o mantinha, tal qual o 'prazer', recorrente, nas edições analisadas. 
Em "Acabe com suas dúvidas sobre sexo e seja mais feliz na cama" (março de 2005), 'Mulher dia-adia' estabelecia, com o uso do imperativo, a interlocução com a leitora e assumia a posição de protagonista. De forma categórica, afirmava que a leitora tinha dúvidas, era feliz em sua vida sexual; porém, por meio do advérbio de intensidade, indicava que ela poderia ser "mais". Assim, tacitamente, o sentido expresso era de que a leitora não desfrutava de toda a intensidade possível que o sexo poderia lhe oferecer, em virtude de suas dúvidas, cabendo à revista elucidá-las'.

Algumas dessas dúvidas eram: [1] "Os homens pensam mais em sexo do que as mulheres?"; [2] "Por que muitos homens só se preocupam com o próprio prazer, sem dar muita importância para o que a parceira está sentindo?"; [3] "Existe alguma forma de a mulher chegar ao orgasmo mais rápido?"; [4] "Com a chegada da menopausa, o prazer da mulher diminui?".

As indagações voltadas ao masculino [1 e 2] demonstraram intensidade (advérbio "mais"), individualidade (adjetivo "só") e domínio (adjetivo "próprio"), em relação ao sexo e aos temas que compreenderam seu campo semântico, diferentemente daquelas direcionadas estritamente à mulher. Ao feminino, apesar de figurado na frase, o advérbio de intensidade "mais", o adjetivo "rápido" deram ao prazer sexual uma conotação de dificuldade [3], reforçada pelo verbo "diminuir". Enquanto, para os homens, o sexo foi associado a sentidos de presença, quantidade, intensidade e singularidade; para as mulheres, foi relacionado, semanticamente, à satisfação sexual. Entretanto, em grau e quantidade comparativamente menores do que para os homens.

No enunciado "Orgasmo sem Segredos". "Você merece este prazer" (abril de 2005), a preposição ("sem") significava ausência e, por isso, reportava ao campo semântico do explícito. Denotava, portanto, que o prazer da excitação sexual era algo sigiloso, assim como o sexo. Logo, a matéria propunha romper com o interdito, ao publicizá-lo. O texto assinalava, ao mesmo tempo, a carência de informações e daquela sensação pelas leitoras do magazine ("você merece este prazer").

$\mathrm{Se}$, em um primeiro momento, o sentido era de privação de conhecimento e de prazer, em outro, era de possibilidades de informação e de alteração da posição da mulher e de sua vivência na relação sexual. Ademais, o sexo era alçado à informação imprescindível e útil, por isso, o progresso do "nãosaber" à posição de mulher ativa trazia como recompensa o deleite.

'Mulher dia-a-dia' projetava também beleza e corpo como assuntos caros ao magazine e referidos à imagem do feminino. O título "Especial" "Plástica já" "Melhorar o corpo está ao alcance de todos. Saiba tudo sobre o assunto!!!" (maio de 2005) garantia um status à chamada, ao intitulá-la de "Especial"; além disso, apresentava-a como exclusiva para a leitora. A cirurgia plástica era promovida como procedimento imediato (advérbio "já"), acessível, que aprimoraria o corpo de toda e qualquer pessoa, deslocando o processo de significação da idéia de um procedimento restrito, devido ao seu alto custo, para produzir outro, o de que a cirurgia plástica estava "ao alcance de todos".

Na sequência dos discursos de cuidado com a estética, o texto "cabelos de estrela" evidenciava, pelo menos, dois tipos de cabelos: o de "estrela" e o de não estrela. A metáfora utilizada transferia atributos ao cabelo, qualificando-os positivamente, e denominava a mulher de bela ou atriz famosa, e a tornava uma referência a ser seguida por ter "cabelos de estrela". A extensão do enunciado - "Com a escova progressiva" - garantia a fórmula para se obterem "cabelos de estrela" e os definia como lisos, pois essa técnica tinha por objetivo esticar e alisar os cabelos. A associação entre cabelo bonito, longo e liso esteve implícita em outras construções, assim como a homogeneização ditada pelo padrão estabelecido pelo magazine.

'Mulher dia-a-dia', por sua vez, no enunciado "Moda, horóscopo, saúde, filhos". "Tudo que você procura está aqui!" (maio, 2005), define o periódico com todas as qualidades possíveis a serem oferecidas à leitora. Entretanto, resume as questões das mulheres aos temas tratados nele - "Moda, horóscopo, saúde, filhos" -, atribuindo à leitora a exigência de ser informada.

Em 'Mulher dia-a-dia', a sexualidade estava mais estritamente relacionada à atividade sexual, ao erotismo e à sensualidade, isto é, ao sexo. Esta incorreu, em alguns momentos, na redução da realização pessoal à liberdade sexual e à possibilidade de ter prazer. 'Claudia', no entanto, sinaliza, de forma sutil, a associação entre sexualidade e condição feminina, bem como os sentimentos decorrentes do lugar ocupado pela mulher por suas atribuições tradicionais na sociedade, como o cuidado e o destaque à relação afetiva. 
Não obstante a semelhança temática, os discursos das revistas sinalizam estágios diferentes de relacionamento afetivo e sexual, e convergem para a apologia de um sentimento predominante na cultura de massa, que é o "amor sintético". O termo foi cunhado por Morin (1997), para designar laços afetivos oriundos da atração sexual e da afinidade das almas na figura do casal. Nessa conformação, o encontro do homem e da mulher simboliza um sentimento total e nuclear.

O "amor sintético", decantado implicitamente nos magazines, representa uma espécie de natureza ao mesmo tempo mitológica e realista. Mitológica, porque é a idealização do relacionamento a dois, propondo que todos os conflitos podem ser superados. E realista, porque retrata a realidade do amor no estilo contemporâneo. Observamos, desse modo, que a promoção do "amor sintético" coincide com a idéia do relacionamento heterossexual, baseado na afeição e consagrado no casamento. Ambas as revistas pressupõem, com isso, um cenário de aceitação social no qual o sexo é liberado, mas, sobretudo, estimulado.

\section{Principais considerações}

'Claudia' e 'Mulher dia-a-dia' cobriram temas comuns, contudo, a primeira enfatiza um discurso de cumplicidade enquanto, a segunda, um discurso pedagógico. Essas características contribuem para compor o sentido do texto (Orlandi, 2001), evidenciando uma das estratificações própria aos produtos culturais, que é a classe social a que eles se destinam.

O discurso de cumplicidade constitui uma enunciação atribuída tanto à revista como à leitora. A essa é concedida a possibilidade de se expressar e, à revista, a posição de informante e comentadora. É desse modo que 'Claudia' transmite valores e uma forma de 'ser mulher' e de 'viver', persuadindo a leitora subliminarmente. Sua posição é a de oferecer possibilidades, dispensando dicas, conselhos e receitas. Da mesma forma, cria uma representação de modernidade e de descolamento em seus discursos, para se fazer entender pela mulher moderna que é a leitora de 'Claudia'.

Por sua vez, o discurso pedagógico busca a utilização sistemática de fórmulas no imperativo, tendo como recurso comum o conselho e a quantificação. A assimetria na interlocução era uma característica da prática discursiva de 'Mulher dia-a-dia', evidenciando tanto uma leitora que se mantinha na condição de aprendiz quanto um dos objetivos da revista, ou seja, difundir valores e instigar desejos. Segundo Orlandi (2001), o uso do imperativo é peculiar a qualquer discurso em que haja 'doutrinação', muito presente nos textos religiosos e, também, no publicitário.

Os discursos privilegiados por 'Claudia' e 'Mulher dia-a-dia', contraditoriamente para este último magazine, são aqueles que enaltecem a posição de sujeito da mulher na relação com o outro. Estes permitiriam à mulher vivenciar sua sexualidade de maneira livre, autônoma, satisfatória e prazerosa. Ambos os periódicos sustentam a importância do protagonismo feminino, notadamente o sexual. Claramente, fica manifesto que o direito de se governar passa, inclusive, pelo autoconhecimento, em nome dos ideais sexuais.

Consideramos que os discursos de 'Claudia' e 'Mulher dia-a-dia' praticamente circunscrevem o debate sobre sexo à presença ou à ausência do prazer sexual ou afetivo. Se por um lado, esse enfoque limita a discussão, por outro, deixa explícito que o prazer é importante para a vida das mulheres e um dos elementos da sexualidade feminina. De todo modo, os magazines perpetuam o clássico enquadramento "Amor e Sexo", identificado em revistas femininas e em estudos sobre esse meio de comunicação de massa (Bassanezi, 1996; Buitoni, 1986). Desse ponto de vista, o sexo se torna, nas reportagens, representativo das transformações femininas na sociedade e, sobretudo, responsável por produzir bem-estar e felicidade.

No entanto, os discursos expostos nas revistas também assinalam aspectos de conservadorismo, veiculando noções e valores que recaem em um moralismo que suporíamos já superado. Ademais, as convenções discursivas dos magazines materializam posições duais sobre a dinâmica sexual contemporânea e ocidental, como: adoção de práticas sexuais simétricas versus vigência de práticas sexuais assimétricas; autonomia sexual feminina versus dependência sexual feminina; atividade versus passividade; prazer feminino versus prazer masculino; espontaneidade versus prescrição. 
Ressaltamos que 'Claudia' e 'Mulher dia-a-dia' manifestam um processo de mudança e de permanência mais amplo, que não deriva nem termina na difusão das formas simbólicas de informação e conhecimento, mas do qual ela se torna seu porta voz. Próprio da dinâmica histórica da sociedade, esse processo reedita novas normatizações dirigidas ao exercício da sexualidade, contribuindo, assim, para formas contemporâneas de subjetivação e de estética. Contudo, o novo traz, no seu interior, resquícios de uma realidade que lhe deu procedência e que se mantém na representação e nas práticas das mulheres, reafirmando seu lugar na sociedade e sua identidade sexual.

\section{Colaboradores}

A autora Luciana Patrícia Zucco participou da elaboração do artigo, de sua discussão e redação e da revisão do texto. A autora Maria Cecília de Souza Minayo participou da revisão bibliográfica, de discussões e revisão do texto.

\section{Referências}

BASSANEZI, C. Virando as páginas, revendo as mulheres: revistas femininas e relações homem mulher 1945 1964. Rio de Janeiro: Civilização Brasileira, 1996.

BOZON, M. Sociologia da sexualidade. Rio de Janeiro: Editora FGV, 2004.

BUITONI, D. S. Imprensa feminina. São Paulo: Editora Ática, 1986.

BUTLER, J. P. Problemas de gênero: feminismo e subversão da identidade. Rio de Janeiro: Civilização Brasileira, 2003.

CALDAS COULTHARD, C.R. O picante sabor do proibido: narrativas pessoais e transgressão. In: FUNCK, S.B.; WIDHOLZER, N. (Orgs.). Gênero em discurso da mídia. Florianópolis: Ed. Mulheres/Santa Cruz do Sul/EDUNISC, 2005. p.121 46.

ETCOFF, N. et al. A verdade sobre a beleza: um relatório global. 2004. Disponível em: <http://www.campanhapelarealbeleza.com.br/uploadedFiles/br/ dove_white_paper_final.pdf >. Acesso em: 10 abr. 2006.

FAIRCLOUGH, N. Discurso e mudança social. Brasília: Editora Universidade de Brasília, 2001.

FOUCAULT, M. História da sexualidade I: a vontade de saber. Rio de Janeiro: Edições Graal, 1999

FRIEDAN, B. Mística feminina. Petrópolis: Vozes, 1971.

FUJISAWA, M.S. Das Amélias às mulheres multifuncionais: a emancipação feminina e os comerciais de televisão. São Paulo: Summus, 2006.

GIDDENS, A. A transformação da intimidade: sexualidade, amor e erotismo nas sociedades modernas. São Paulo: Editora da Universidade Estadual Paulista, 1993.

HEILBORN, M.L. Construção de si, gênero e sexualidade. In: . (Org.). Sexualidade: o olhar das Ciências Sociais. Rio de Janeiro: Jorge Zahar, 1999. p.40-58.

Gênero, sexualidade e saúde. In: SILVA, D.P.M. (Org.). Saúde, sexualidade e reprodução: compartilhando responsabilidades. Rio de Janeiro: Universidade do Estado do Rio de Janeiro, 1996. p.101-10.

MEDRADO, B. Discursos sobre o masculino: um panorama da masculinidade nos comerciais de TV. Lugar Comum - Estud. midia, cult. democr., n.23, p.161-78, 1997. 
MELO, J. Relatório sobre o capítulo J - A mulher e os meios de comunicação.

Plataforma de Ação de Pequim. In: CONFERÊNCIA MUNDIAL SOBRE A MULHER, 4. , 2000. Disponível em: <http://www.patriciagalvao.org.br/>. Acesso em: 20 fev. 2006.

MINAYO, M.C.S. O desafio do conhecimento: pesquisa qualitativa em saúde. 10.ed. São Paulo: Hucitec, 2007.

MIRA, M.C. O masculino e o feminino nas narrativas da cultura de massas ou o deslocamento do olhar. Cad. Pagu, n.21, p.13-38, 2003.

MONTEIRO, M. Revistas masculinas e pluralização da masculinidade entre os anos 1960 e 1990. Lugar Comum - Estud. midia, cult. democr, n.12, p.87-103, 2000.

MORIN, E. Cultura de massas no século XX: neurose. Rio de Janeiro: Forense Universitária, 1997. v.1.

ORLANDI, E.P. A linguagem e seu funcionamento: as formas do discurso. Campinas: Pontes, 2001.

Análise de discurso: princípios e procedimentos. Campinas: Pontes, 1999.

SARTI, C.; MORAES, M.Q. Aí a porca torce o rabo. In: BRUSCHINI, C.; ROSEMBERG, F. (Orgs.). Vivência: história, sexualidade e imagens femininas. São Paulo: Brasiliense, 1980. p.19-57.

SWAIN, T.N. Feminismo e recortes do tempo presente: mulheres em revistas femininas. São Paulo Perspec., v.15, n.3, p.1-27, 2001.

THOMPSON, J.B. A mídia e a modernidade: uma teoria social da mídia. Petrópolis: Vozes, 1998.

WIDHOLZER, N. A publicidade como pedagogia cultural e tecnologia de gênero: abordagem lingüístico discursiva. In: FUNCK, S.B.; WIDHOLZER, N. (Orgs.). Gênero em discurso da mídia. Florianópolis: Ed. Mulheres, 2005. p.17-52.

\section{Sites consultados}

EDITORA ABRIL. Disponível em: <http://www.abril.com.br>. Acesso em: 2 ago. 2003.

EDITORA ALTO ASTRAL. Disponível em: <http://www.editoraaltoastral.com.br>. Acesso em 3 jun. 2006.

ZUCCO, L.P.; MINAYO, M.C.S. Sexualidad femenina en revista(s). Interface - Comunic., Saúde, Educ., v.13, n.28, p.43-54, jan./mar. 2009.

Este artículo es resultado de la investigación de los discursos de la sexualidad femenina difundidos por revistas para mujeres en el periodo de 2005 y 2006. "Claudia" y "Mujer día-a-día" han sido los documentos analizados en una aproximación cualitativa de pesquisa. La construcción de los datos se ha efectuado por medio del análisis crítico del discurso, encarándose la sexualidad femenina a partir de una lectura constructivista. Los principales resultados han puesto en evidencia que las convenciones discursivas presentes en los reportajes materializan posiciones duales sobre lá dinámica sexual contemporánea y occidental como: adopción de prácticas sexuales simétricas en comparación con vigencia de prácticas asimétricas; autonomía sexual femenina en comparación con dependencia sexual femenina; actividad en comparación con pasividad; placer femenino en comparación con placer masculino. Afirmamos, con esto, que la sexualidad permanece doblemente informada por padrones hegemónicos vigentes en la sociedad.

Palabras clave: Sexualidad femenina. Medios de comunicación. Discursos. Publicaciones periódicas. 